\title{
Endometriosis: A Retrospective Analysis of Clinical Data from a Cohort of 4,083 Patients, With Focus on Symptoms
}

\author{
PIETRO G. SIGNORILE ${ }^{1}$, MARIA CASSANO ${ }^{1}$, ROSA VICECONTE ${ }^{1}$, \\ VALENTINA MARCATTILJ ${ }^{1}$ and ALFONSO BALDI ${ }^{1,2}$ \\ ${ }^{1}$ Italian Endometriosis Foundation, Rome, Italy; \\ ${ }^{2}$ Department of Environmental, Biological and Pharmaceutical Sciences and Technologies, \\ Università della Campania L. Vanvitelli, Caserta, Italy
}

\begin{abstract}
Background: Endometriosis is an estrogendependent and chronic inflammatory gynecological disease due to the presence of ectopic endometrial tissue outside the uterine cavity. This disease affects approximately $10 \%$ of the female population. In spite of its relatively high prevalence, information about its pathogenesis, diagnosis, and therapy is not complete. Patients and Methods: We present a retrospective study performed on 4,083 patients with endometriosis, with a focus on symptoms. The archived data were analyzed investigating the distribution of symptoms among patients, the correlation of symptoms with the occupation of the patients, and finally the correlation with the other anamnestic data. Statistical associations between the data for all cases were then considered separately. Results: Chronic fatigue syndrome and dyspareunia were confirmed as being among the main symptoms of endometriosis, together with bowel disorders. On the other hand, we registered a low occurrence of urinary disorders and even of chronic pelvic pain, which is usually considered among the main symptoms of endometriosis. We found an increase in incidence of symptoms starting from the age group 25-29 years up to 40-44 years and, subsequently, a significant decrease in the group aged 55-59 years. For all the symptoms analyzed, we found a higher incidence in employers, graduates and freelancers. Finally, we found a protective effect of the number of gestations on chronic fatigue syndrome. Conclusion: This in-depth study on such a vast cohort of affected patients clarifies some important
\end{abstract}

This article is freely accessible online.

Correspondence to: Pietro G. Signorile, Via degli Olmetti 46, Formello 00060 Rome, Italy. E-mail: research@endometriosi.it

Key Words: Endometriosis, adenomyosis, chronic pelvic pain, chronic fatigue, bowel disorders, bladder pain, stress, depression, anxiety. aspects on the complex symptomatology of this still enigmatic disease. In particular, the study highlights the symptoms most closely related to endometriosis which will help speed up the diagnostic process of patients suffering from this pathology.

Endometriosis is a chronic inflammatory, estrogen-dependent gynecological disease that affects up to $10 \%$ of all women (1). This prevalence increases to $30-50 \%$ in women also suffering from chronic pelvic pain and infertility $(2,3)$. The peculiar phenotype of endometriosis is the growth of ectopic endometrial-like tissue outside of the uterine cavity. As recently described in a study on a wide cohort of patients with endometriosis, the highest prevalence of endometriosis involves the deep peritoneum, in agreement with what is generally known about the main locations of endometriosis implants (4), while the superficial peritoneum has a low prevalence. A similar incongruity between superficial and deep tissues is also observed for the ovaries. Moreover, the incidence of endometriotic lesions is also significant in the pouch of Douglas (4). This last particular condition in which endometriotic lesions are present under the peritoneum, called deep-penetrating endometriosis, is strongly associated with pelvic pain symptoms (5).

Patients with endometriosis have an extended clinical history of infertility and suffer numerous aching symptoms, especially during menstruation and intercourse. Affected patients frequently require extensive medical and surgical treatments, with substantial related costs and risks (6). For all these reasons, endometriosis has important socioeconomic consequences with harmful effects upon women's working activity, personal life, and relationships with medical practitioners (6).

Despite the fact that this disease is very common and has a great social impact, the pathogenesis, as well as the diagnosis and therapy are still not perfectly delineated. Retrograde menstruation and coelomic metaplasia are the most recognized hypotheses for pathogenesis (7). In recent 
years, research conducted by our group and others have produced experimental evidence in favor of an alteration of the fine-tuning of the female genital system development during fetal life as the pathogenic event predisposing to the progression of endometriosis later in life (8-13). This model is also strengthened by the increase in the incidence of endometriosis in patients presenting uterine malformations (14). Lastly, using a genomic approach to analyze the transcriptional profiling of the ectopic endometrium with respect to the corresponding ectopic one, our research group has demonstrated that several genes implicated in embryogenesis are differentially expressed in endometriotic tissues and that this expression pattern is not linked to the menstrual and hormonal phases (15).

Due to the lack of information about this disease, endometriosis is an unbelievably underdiagnosed and undertreated condition, with an unreasonably long interval (8-12 years) between the commencement of the symptoms and a definitive diagnosis (16). This is because most of the symptoms are non-specific and, at present, there are no noninvasive diagnostic tests capable of providing a definitive diagnosis (17). Furthermore, although the symptoms of this disease are known, there are no observations on large cohorts of patients which analyzed the symptoms and their course in patients in relation to the age of onset and throughout their reproductive life. Nevertheless, our research group recently proposed some possible candidates as molecular diagnostic markers (18-20). Nowadays, the diagnosis of endometriosis can be achieved exclusively through histological examination of ectopic implants obtained by invasive surgical or laparoscopic procedures.

This article presents a retrospective study conducted on a substantial cohort of patients with endometriosis, referred during a period of over 10 years (from 2000 to 2010). The entire cohort consisted of 4,401 patients, 584 of whom had undergone laparoscopic surgery for therapeutic purposes; a total of 4,083 of these patients had full follow-up data. In this article, we analyzed the frequency of the different symptoms declared by the patients in detail and correlated them with the age of onset. We also studied the course of symptoms over their reproductive lives in order to obtain more detailed information on how and when these symptoms occurred. The results are discussed considering the existing literature.

\section{Patients and Methods}

Study design. This retrospective evaluation was performed on a cohort of 4,083 patients with endometriosis that visited the Italian Endometriosis Center in the period 2000-2010. The study was conducted in accordance with the Helsinki Declaration of 1975, as revised in 2000 and 2008, and was approved by the Scientific Committee of Fondazione Italiana Endometriosi. All patients provided written-informed consent before enrollment in the study to permit the use of the data generated in retrospective analyses. Briefly, the patients, upon accessing the Center, filled out a form where all their data were collected in relation to endometriosis they may have had. A detailed questionnaire was administered to all patients with the aim of collecting anamnestic data and precisely defining the symptoms. The questionnaire was administered by trained medical personnel.

A non-invasive diagnostic protocol was performed which included vaginal examination with accurate screening of the fornixes of the cervix and the virtual space of the rectal vaginal septum, followed by rectal exploration with screening of the perineum, of the deep rectal canal, of the posterior wall of the uterus, utero-sacral ligaments and inferior branch of Mackenrodt's ligament. Magnetic resonance imaging was then performed to diagnose any ovarian endometriosis and the upper part of the uterus that escapes the bimanual examinations. Finally, blood tests were prescribed to check serum markers cancer antigen 125, cancer antigen 19.9, homocysteine, 17 $\beta$ estradiol, vitamin $\mathrm{D}$, anti-Mullerian hormone, free triiodothyronine3 , free triiodothyronine-4, thyroid-stimulating hormone, anti-thyroid antibodies and anti-peroxidase.

Statistical analysis. Descriptive analyses of the distribution of symptoms among patients are presented via histograms, as well as the prevalence of symptoms in patients by age class and occupation.

In order to detect possible associations between the presence of symptoms in patients and their initial anamnesis, the Pearson's chisquare test was used. When necessary, the Haldane-Anscombe correction for small groups was applied, as some of the frequencies in the contingency tables were zeros. These analyses were performed using Python 3.7.12 libraries pandas, scipy.stats and statistics (Python Software Foundation, Wilmington, DE, USA).

When a significant association was detected via the chi-square test, a further inspection of the magnitude and direction of the association was performed using the logistic regression model with estimated odds ratios. These analyses were performed using R 4.1.1 glm function (binomial family). In all analyses, a $p$-value below 0.05 was associated with statistical significance.

Logistic regression is commonly used to model a binary outcome, in our case, the presence or absence of a specific symptom. We used ordinal anamnesis variables (i.e., variables that have two or more ordered categories) that showed a general association with a specific symptom, evaluated earlier via Pearson's chi-square test, as predictors of the probability of having that symptom. In our case, we compared each category of the predictor variable with its reference group (i.e., the lowest category). Therefore, the estimated coefficients give the log-odds of the outcome when belonging to a higher category group of the predictor compared to its reference group.

In order to facilitate interpretation of the results, we decided to exponentiate the coefficient in order to provide the actual odds ratios of having the symptom for a one-category increase of the predictor variable.

\section{Results}

Anamnestic data. All data produced with the anamnestic analysis are described in a different article (4). Briefly, data were registered concerning age of the patients, age at menarche, number of children, occupation of the patients, 
Table I. Characteristics of the enrolled patients.

\begin{tabular}{|c|c|c|c|}
\hline & & Subgroup & Frequency, n (\%) \\
\hline \multirow{18}{*}{$\begin{array}{l}\text { Demographic } \\
\text { data }(\mathrm{N}=4,401)\end{array}$} & \multirow{11}{*}{ Age, years } & $<20$ & $4(<1 \%)$ \\
\hline & & $20-24$ & $38(1 \%)$ \\
\hline & & $25-29$ & $151(3 \%)$ \\
\hline & & $30-34$ & $414(9 \%)$ \\
\hline & & $35-39$ & $804(18 \%)$ \\
\hline & & $40-44$ & $1,082(25 \%)$ \\
\hline & & $45-49$ & $878(20 \%)$ \\
\hline & & $50-54$ & $386(9 \%)$ \\
\hline & & $55-59$ & $96(2 \%)$ \\
\hline & & $\geq 60$ & $18(<1 \%)$ \\
\hline & & Not known & $530(12 \%)$ \\
\hline & \multirow[t]{7}{*}{ Occupation } & Employee & $1,800(41 \%)$ \\
\hline & & Freelancer & $1,112(25 \%)$ \\
\hline & & Housewife/retired & $570(13 \%)$ \\
\hline & & Student & $396(9 \%)$ \\
\hline & & Business owner & $184(4 \%)$ \\
\hline & & Unemployed & $11(<1 \%)$ \\
\hline & & Not known & $328(7 \%)$ \\
\hline \multirow{24}{*}{$\begin{array}{l}\text { Clinical data } \\
(\mathrm{N}=4,311)\end{array}$} & \multirow{5}{*}{$\begin{array}{l}\text { Age at } \\
\text { menarche, } \\
\text { years }\end{array}$} & $<10$ & $454(11 \%)$ \\
\hline & & $<12$ & $1,962(46 \%)$ \\
\hline & & $<14$ & $1,517(35 \%)$ \\
\hline & & $>14$ & $236(5 \%)$ \\
\hline & & Not known & $142(3 \%)$ \\
\hline & \multirow[t]{4}{*}{ Children } & None & $199(5 \%)$ \\
\hline & & One & $502(12 \%)$ \\
\hline & & Two or more & $382(9 \%)$ \\
\hline & & Not known & $3,228(75 \%)$ \\
\hline & \multirow{4}{*}{$\begin{array}{l}\text { Surgery for } \\
\text { endometriosis } \\
\text { Immune } \\
\text { disorder }\end{array}$} & No & $1,938(45 \%)$ \\
\hline & & Yes & $2,373(55 \%)$ \\
\hline & & No & $2,652(62 \%)$ \\
\hline & & Yes & $1,659(38 \%)$ \\
\hline & \multirow{4}{*}{$\begin{array}{c}\text { Treatment with } \\
\text { contraceptive } \\
\text { pill }\end{array}$} & $\leq 60$ Months & $2,111(49 \%)$ \\
\hline & & 61-120 Months & $937(22 \%)$ \\
\hline & & >120 Months & $432(10 \%)$ \\
\hline & & Not known & $831(19 \%)$ \\
\hline & \multirow{7}{*}{$\begin{array}{l}\text { Treatment } \\
\text { with hormone } \\
\text { analogs } \\
\text { Ovarian } \\
\text { stimulation }\end{array}$} & No & $3,253(75 \%)$ \\
\hline & & $\leq 6$ Months & $730(17 \%)$ \\
\hline & & $>6$ Months & $328(8 \%)$ \\
\hline & & None & $2,658(62 \%)$ \\
\hline & & One & $56(1 \%)$ \\
\hline & & Two or more & $162(4 \%)$ \\
\hline & & Not known & $1,435(33 \%)$ \\
\hline
\end{tabular}

Data modified from (4).

presence of concomitant immune disorders, period of contraceptive pill treatment, number of ovarian stimulations, period of treatment with hormone analogs. Table $\mathrm{I}$ is modified form the work by Signorile et al. (4) and summarizes the anamnestic data of the whole patient cohort.

Reported symptoms. Table II lists the data regarding the endometriosis-related symptoms declared by the majority $(\sim 95 \%)$ of the patient cohort. Most of these patients were symptomatic. Bowel disorders were confirmed as being
Table II. Distribution of symptoms among patients who had full followup data $(N=4,083)$.

\begin{tabular}{lcc}
\hline Symptom & Present, n (\%) & Absent, n (\%) \\
\hline $\begin{array}{l}\text { Swollen abdomen (dyspareunia } \\
\text { and abdominal pain) }\end{array}$ & $2,652(65 \%)$ & $1,431(35 \%)$ \\
Asthenia (chronic fatigue syndrome) & $2,526(62 \%)$ & $1,557(38 \%)$ \\
$\begin{array}{l}\text { Dyspareunia } \\
\text { Rectal pain }\end{array}$ & $2,273(56 \%)$ & $1,810(44 \%)$ \\
Bowel dysfunctions & $2,141(52 \%)$ & $1,942(48 \%)$ \\
(constipation or diarrhea) & $2,125(52 \%)$ & $1,958(48 \%)$ \\
Migraine & $1,900(47 \%)$ & $2,183(53 \%)$ \\
Ovulatory pain & $1,877(46 \%)$ & $2,206(54 \%)$ \\
Chronic pelvic pain & $1,071(26 \%)$ & $3,012(74 \%)$ \\
Cystitis & $913(22 \%)$ & $3,170(78 \%)$ \\
Denied typical symptoms & $240(6 \%)$ & $3,843(94 \%)$ \\
Bladder pain & $144(4 \%)$ & $3,939(96 \%)$ \\
\hline
\end{tabular}

among the main symptoms of endometriosis, followed by chronic fatigue syndrome and dyspareunia. In the tables, we used the term 'swollen abdomen' to cover different possible bowel disorders, including dysmenorrhea and abdominal pain; the term 'asthenia' includes all the symptoms related to chronic fatigue syndrome. Bladder pain was the least frequent symptom, after cystitis. Finally, chronic pelvic pain was reported by only about one quarter of the subjects of this study.

Distribution of symptoms by age of patients. We evaluated the distribution of symptoms by the age of patients. As reported in Figure 1, for all the symptoms, we found an increase in incidence from the age group 25-29 years up to 40-44 years and, subsequently, a significant decrease in the age group 55-59 years. As expected, the youngest and oldest age groups showed a very low or no incidence of symptoms.

Distribution of symptoms by professional activity. For all the symptoms analyzed, we found a higher incidence in employers, graduates and freelancers. On the other hand, the incidence was significantly lower in housewives, pensioners, students and the unemployed. Interestingly, the incidence was also low in the category businesswoman and business owner. Figure 2 summarizes all the data produced by this analysis.

Association between symptoms and clinical and anamnestic data. Regarding swollen abdomen and absence of typical symptoms, we found a similar protective effect of an increasing number of children, while this effect was stronger for asthenia. Conversely, we registered an opposite association between chronic pelvic pain and the number of children (Table III). 


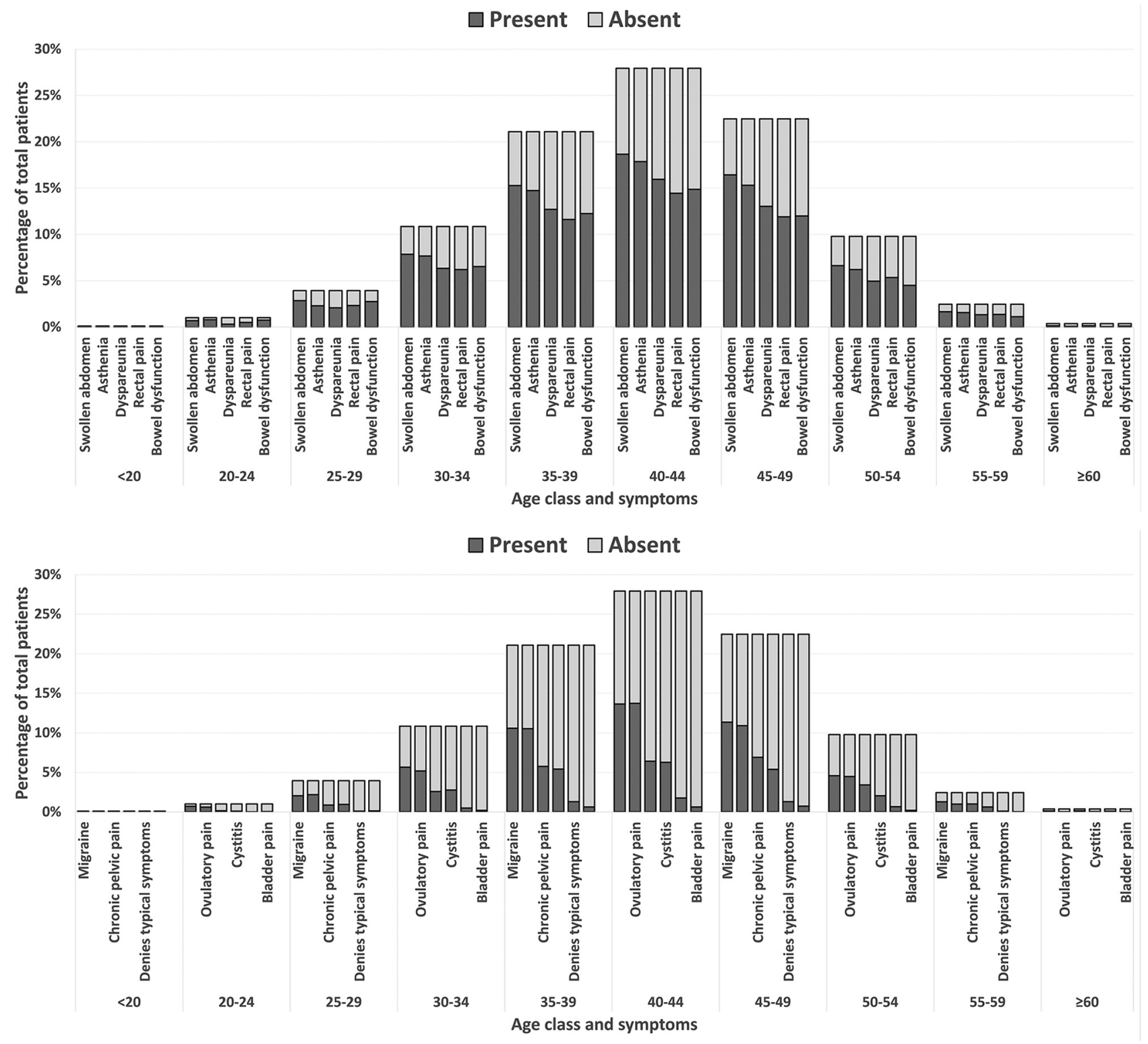

Figure 1. Histograms showing the frequency of swollen abdomen, asthenia, dyspareunia, rectal pain, bowel dysfunction, migraine, ovulatory pain, chronic pelvic pain, cystitis, denial of typical symptoms, and bladder pain in patients by age class.

Moreover, a protective effect was found for the association between ovulatory pain and the use of contraceptive pill. This last factor was also positively correlated with the absence of typical symptoms. The duration of treatment with hormone analogs showed a protective effect on bowel dysfunction, while it increased the odds of having chronic pelvic pain. Interestingly, the duration of treatment with a contraceptive pill increased the odds of having rectal pain. Finally, a later age at menarche had a protective effect on dyspareunia and bladder pain (Table IV).

\section{Discussion}

The most common symptoms (reported by $>50 \%$ of the patients) were pelvic pain, dyspareunia, and bowel alterations; this confirms the general knowledge $(21,22)$ that endometriosis is mainly associated with pain (in symptomatic cases, as mentioned above), especially regarding the incidence of chronic pelvic pain (23), and bowel disorders. A state of chronic inflammation seems to be the basis of the painful symptomatology. Recently, our research group 


\section{Swollen abdomen}

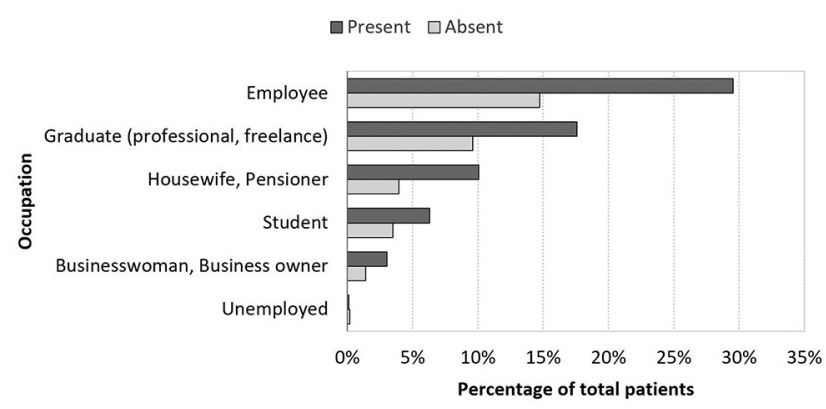

Dyspareunia

$\square$ Present $\square$ Absent

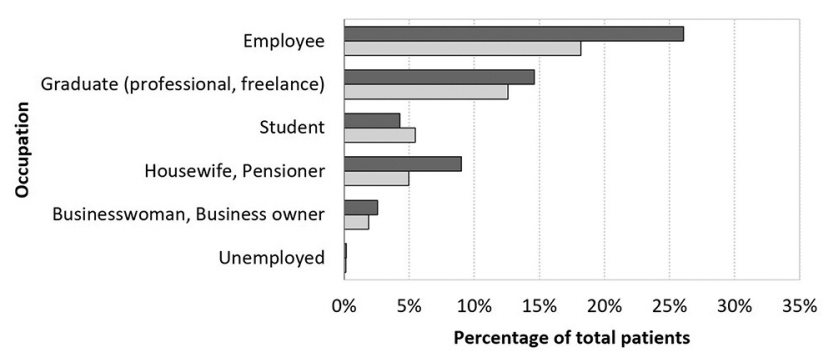

Bowel dysfunctions (constipation or diarrhea)

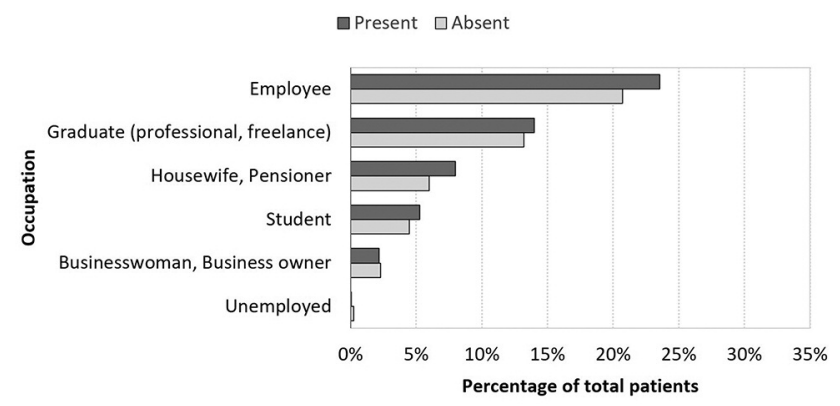

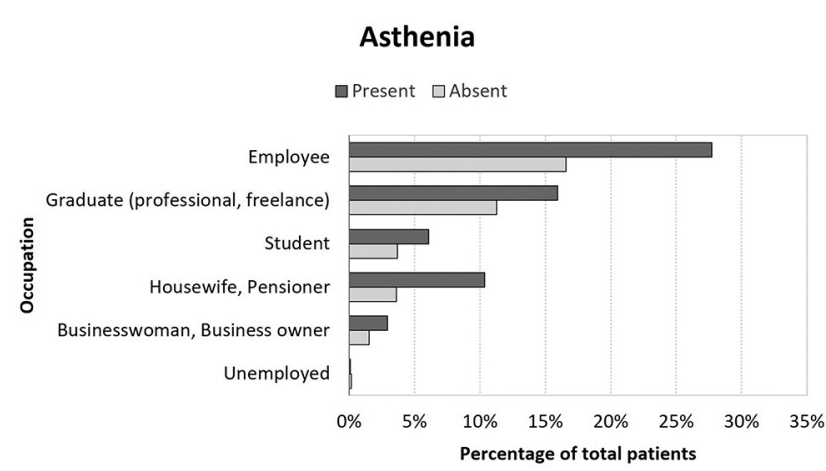

Rectal pain

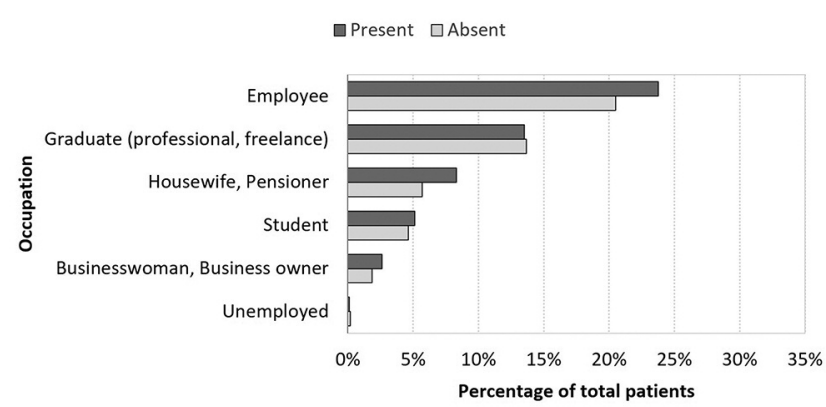

Figure 2. Continued

demonstrated that a specific diet regimen and dedicated food supplementation seem to have a positive effect on the intensity of symptoms by reducing inflammation (24). In the pathogenesis of pain symptoms, there is also a role of pelvic factors, such as the growth of new nerve fibers, peritoneal fluid and inflammation, which is accompanied by a role of the central nervous system and associated systems, including the stress axis and psychological factors (25).

However, we also noted that asthenia was among the most frequently reported symptoms. This is in agreement with studies reporting significant comorbidity between endometriosis and fatigue/chronic fatigue syndrome $(26,27)$ due to excessive function of the immune system as a response to continuous, silent inflammation determined by the presence of the disease $(1,2)$. Bladder pain was the least frequent symptom, as evidence of the lower incidence in the anterior compartment and more frequent incidence of the presence of endometriosis in the posterior compartment probably due to factors related to the embryonic origin of the disease $(4,13,14)$. According to this pathogenic mechanism, the dissemination of endometrial cells outside the uterus would take place especially in the last phase of closure of the two hemi-uteri, which is realized with the closure of the posterior wall (28). We also found a low incidence of cystitis, in contrast with studies attributing endometriosis with an increased risk for urinary disorders (29) or, at least, 


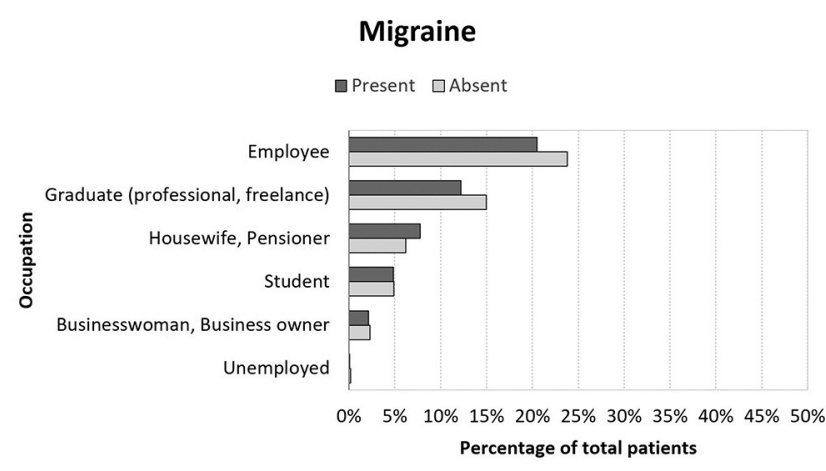

Chronic pelvic pain

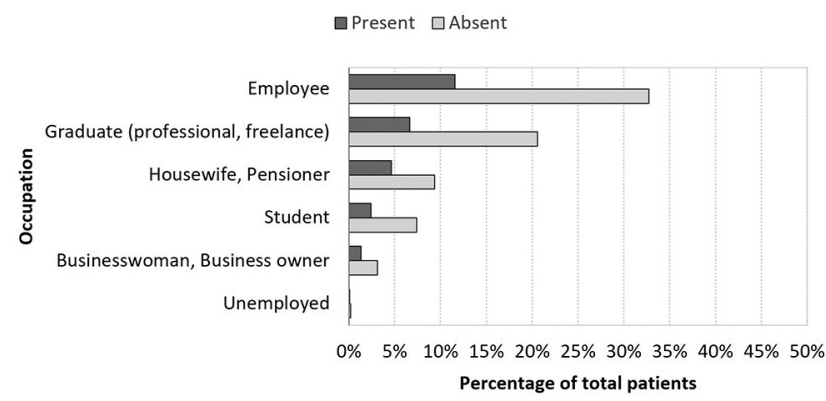

Denied typical symptoms

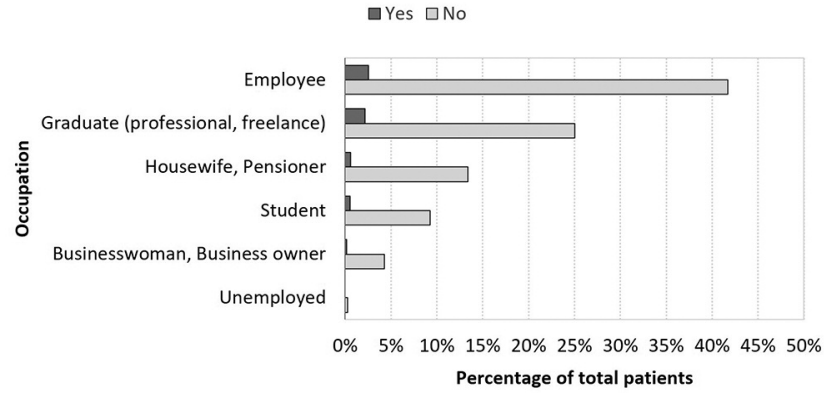

Ovulatory pain

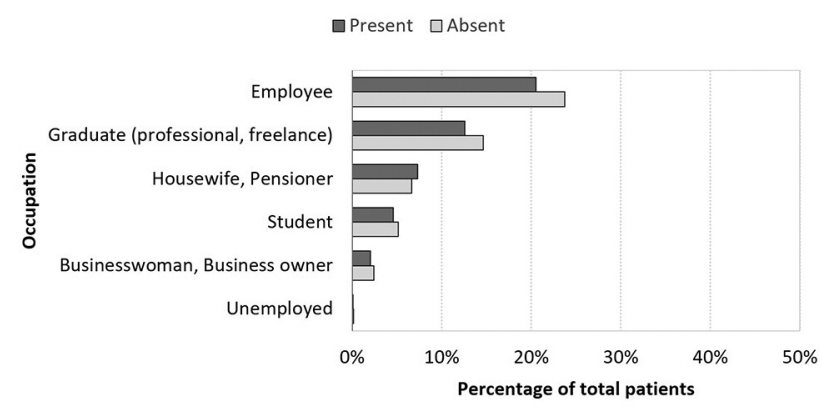

Cystitis

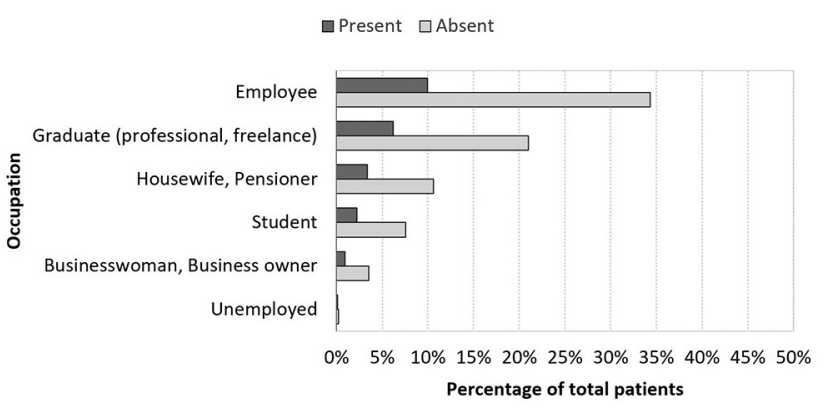

Bladder pain

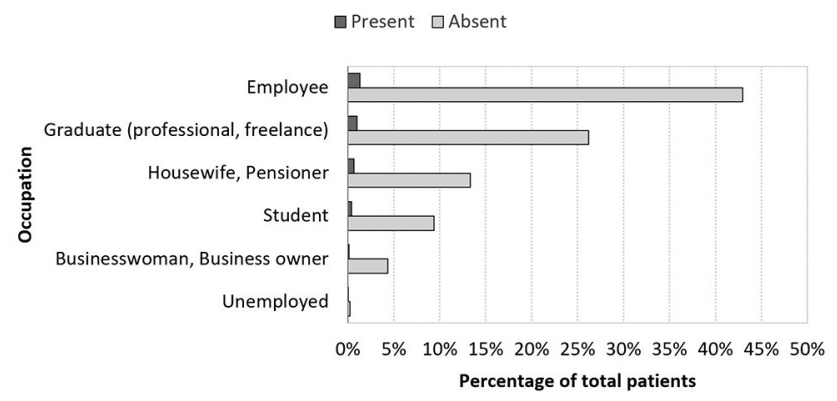

Figure 2. Histograms showing the distribution of symptoms of swollen abdomen, asthenia, dyspareunia, rectal pain, bowel dysfunction, migraine, ovulatory pain, chronic pelvic pain, cystitis, denial of typical symptoms, and bladder pain in patients by occupation.

reporting a prevalence in their coexistence (30). Note also that chronic pelvic pain, often reported $(31,32)$ as one of the three main types of endometriosis-related pain with an incidence of $40-60 \%$ (33), was reported by only about one quarter of the subjects of our study. Nonetheless, in contrast with previous reports, the incidence of urinary disorders and pelvic pain was low. These findings shed new light upon the common symptomatology of endometriosis.

Concerning the distribution of symptoms by age of patients, we have described a characteristic trend that demonstrates how in the first years of reproductive life, these symptoms have the same trend in relation to age. In particular, the symptoms seem poorly reported up to the age of 25 years. They are present in a significant way only starting from the age group of 25-29 years, reaching a maximum peak in the 40- to 44-year-old group, with a steady decline to the age group of 50-54 years, the age of menopause. This trend can be linked to ovarian estrogenic hormonal activity and may explain the delay in diagnosis of this disease in young women. Alternatively, it is possible to hypothesize that the disease being in an initial clinical form in young patients, determines fewer symptoms compared to the disease in an advanced stage (34).

Accuracy, insistence and patience in the anamnestic collection of the symptoms of endometriosis would seem to be an important step when dealing with a young patient in 
Table III. Overall significance of associations tested via Pearson's chi-square test. $p$ Values of less than 0.05 were considered significant. Correction for zeroes in the contingency tables were performed when necessary.

\begin{tabular}{|c|c|c|c|}
\hline Symptom & Associated anamnesis & Chi-square value & $p$-Value \\
\hline Swollen abdomen* & Number of children & 6.83 & $<0.05$ \\
\hline Asthenia** & Number of children & 11.09 & $<0.01$ \\
\hline Dyspareunia & Age at menarche & 10.74 & $<0.05$ \\
\hline \multirow[t]{2}{*}{ Rectal pain } & Number of children & 7.51 & $<0.05$ \\
\hline & Period of treatment with contraceptive pill & 25.73 & $<0.001$ \\
\hline \multirow[t]{3}{*}{ Bowel dysfunction*** } & Number of children & 12.59 & $<0.01$ \\
\hline & Endometriosis surgery & 39.65 & $<0.001$ \\
\hline & Period of treatment with analogs & 10.70 & $<0.01$ \\
\hline \multirow[t]{2}{*}{ Migraine } & Number of children & 7.21 & $<0.05$ \\
\hline & Age at menarche & 12.36 & $<0.01$ \\
\hline \multirow[t]{2}{*}{ Ovulatory pain } & Endometriosis surgery & 10.43 & $<0.01$ \\
\hline & Period of treatment with contraceptive pill & 14.08 & $<0.001$ \\
\hline \multirow[t]{3}{*}{ Chronic pelvic pain } & Number of children & 38.45 & $<0.001$ \\
\hline & Endometriosis surgery & 8.65 & $<0.01$ \\
\hline & Period of treatment with analogs & 37.12 & $<0.001$ \\
\hline Cystitis & Number of children & 6.44 & $<0.05$ \\
\hline \multirow[t]{2}{*}{ Denied typical symptoms } & Number of children & 6.01 & $<0.05$ \\
\hline & Period of contraceptive pill treatment & 6.73 & $<0.05$ \\
\hline \multirow[t]{2}{*}{ Bladder pain } & Age at menarche & 9.77 & $<0.05$ \\
\hline & Endometriosis surgery & 10.98 & $<0.001$ \\
\hline
\end{tabular}

*Dyspareunia and abdominal pain. $* *$ Chronic fatigue syndrome. $* * *$ Constipation or diarrhea.

Table IV. Associations tested via logistic regression, for the relevant predictor variables.

\begin{tabular}{|c|c|c|c|c|}
\hline Symptom & $\begin{array}{c}\text { Associated anamnesis, confirmed } \\
\text { via logistic regression }\end{array}$ & $\begin{array}{l}\text { Factor for which } \\
\text { the association was significant }\end{array}$ & OR $(95 \% \mathrm{CI})$ & $p$-Value \\
\hline Swollen abdomen* & Number of children & $1 \mathrm{vs}$. None & $0.70(0.48-0.99)$ & $<0.05$ \\
\hline Asthenia** & Number of children & $\geq 2 v s$. None & $1.73(1.19-2.50)$ & $<0.01$ \\
\hline \multirow[t]{2}{*}{ Dyspareunia } & Age at menarche & $<12$ vs. $<10$ Years & $0.74(0.59-0.91)$ & $<0.01$ \\
\hline & & $<14$ vs. $<10$ Years & $0.75(0.60-0.94)$ & $<0.05$ \\
\hline \multirow[t]{2}{*}{ Rectal pain } & Treatment with contraceptive pill & $61-120$ vs. $\leq 60$ Months & $1.36(1.16-1.59)$ & $<0.001$ \\
\hline & & $>120$ vs. $\leq 60$ Months & $1.58(1.27-1.96)$ & $<0.001$ \\
\hline \multirow[t]{3}{*}{ Bowel dysfunction*** } & Number of children & 1 vs. None & $0.54(0.39-0.77)$ & $<0.001$ \\
\hline & & $\geq 2 v s$. None & $0.70(0.49-0.99)$ & $<0.05$ \\
\hline & Treatment with hormone analogs & $\leq 6$ Months vs. none & $0.77(0.65-0.91)$ & $<0.01$ \\
\hline \multirow[t]{3}{*}{ Migraine } & Number of children & $\geq 2 v s$. None & $1.50(1.06-2.12)$ & $<0.05$ \\
\hline & Age at menarche & $<12$ vs. $<10$ Years & $0.74(0.59-0.91)$ & $<0.01$ \\
\hline & & $<14$ vs. $<10$ Years & $0.75(0.60-0.94)$ & $<0.05$ \\
\hline \multirow[t]{2}{*}{ Ovulatory pain } & Treatment with contraceptive pill & $61-120 v s . \leq 60$ Months & $0.77(0.66-0.91)$ & $<0.01$ \\
\hline & & $>120 v s . \leq 60$ Months & $0.75(0.60-0.93)$ & $<0.01$ \\
\hline \multirow[t]{4}{*}{ Chronic pelvic pain } & Number of children & $1 \mathrm{vs}$. None & $2.70(1.75-4.32)$ & $<0.001$ \\
\hline & & $\geq 2$ vs. None & $4.01(2.57-6.44)$ & $<0.001$ \\
\hline & Treatment with hormone analogs & $\leq 6$ Months $v s$. none & $1.55(1.30-1.85)$ & $<0.001$ \\
\hline & & $>6$ Months $v s$. none & $1.74(1.36-2.23)$ & $<0.001$ \\
\hline
\end{tabular}

CI: Confidence interval; OR: odds ratio. *Dyspareunia and abdominal pain. **Chronic fatigue syndrome. ${ }^{* * *}$ Constipation or diarrhea.

order to appropriately emphasize relevant symptoms. Such attention might reduce the tremendous diagnostic delay that afflicts patients with this disease.

Concerning the distribution of symptoms by professional activity, we found a clear prevalence of symptoms in some classes of patients and a lower incidence in the perception of symptoms in other classes in relation to their occupation. We described a lower incidence of symptoms in the groups of patients who did not work (housewives, retirees, students, unemployed) compared to patients who did. This observation 
implies that external factors such as strong commitment and stress might contribute to an increase in pain perception (35). In addition, the prevalence of the presence of symptoms based on the occupation is homogeneous, meaning that the type of occupation influences the symptoms regardless of the type of symptom.

It is well known that stress affects the physiology of the pelvic organs and disturbs the hypothalamic-pituitary-adrenal axis, leading to chronic, painful, and inflammatory disorders (36). The results of the negative impact of endometriosis symptoms on quality of life, work/study productivity, and personal relationships in turn cause high levels of psychological and emotional distress $(26,27)$. The stressinflammation-pain crosstalk through the hypothalamicpituitary-adrenal axis activity indicates that stress relief should affect inflammation and, in turn, reduce pain responses (37).

Furthermore, women with endometriosis, particularly those with painful symptoms, have higher stress levels and a reduced quality of life than healthy women. Importantly, depression and anxiety are more prevalent in women with endometriosis, and the presence of psychiatric disorders is more related to the severity of endometriosis-related pain than to other features of the disease. Current evidence indicates that women with endometriosis have a higher prevalence of psychological disorders that correlate more with the pain itself than with endometriosis per se. In addition, effective treatment of endometriosis can reduce the psychological burden of the disease (38).

Medical and surgical treatments of endometriosis also improved perceived stress, anxiety, and depressive symptoms, thereby reducing the psychological burden of the disease (39).

Regarding the association between symptoms and clinical and anamnestic data, we found a significant protective effect of the number of children on asthenia. A possible explanation for this phenomenon is that the changes in the immune function determined by pregnancy can somehow modulate, even after gestation, the female immune response to endometriosis. Furthermore, it can be hypothesized that the psychophysical satisfaction of achieving motherhood is a psychological stimulus to counteract asthenia (40). In contrast, we found a higher prevalence of chronic pelvic pain in cases of women with endometriosis who had one or more gestations. This can be ascribed to the behavior of endometriosis/adenomyosis, especially concerning the greater capacity for microscopic myometrial invasion of endometriosis after pregnancies. All this is due to the architectural and structural changes that take place in the myometrium during and after pregnancy. This phenomenon is especially present in the endometrial-myometrial interface, which is disrupted in adenomyosis (41).

Finally, we found a protective effect for the association between ovulatory pain and the use of contraceptive pills. This association also was observed for pelvic pain and bowel dysfunction. Interestingly, we found an opposite relationship for contraceptive pill use with chronic pelvic pain and rectal pain. This result is in agreement with data from a systematic review of the literature (42) that has not been able to define with certainty the real effectiveness of the use of the contraceptive pill in alleviating pain associated with endometriosis. Regarding the different effect of contraceptive pill use on endometriosis-associated pain found in this study, it is possible to hypothesize a fundamental pathogenetic role of the hyper-estrogenic microenvironment within endometriotic lesions, which is a consequence of an epigenetic regulatory mechanism involving the aromatase gene (43). The greater sensitivity to the metabolization of estrogens by the stromal cells of endometriotic lesions, which constitute most of the deep disease, may justify a greater activation of deep stromal disease, compared to disease present in other sites with a prevalent epithelial composition, in which the mitotic stimulation by estrogens and its proliferative effects may be lower.

In conclusion, this in-depth study on such a vast cohort of affected patients helps to clarify some important aspects on the complex symptomatology of this still enigmatic syndrome, which we propose to define as ectopic endometrial syndrome. In particular, the study highlights the symptoms most closely related to endometriosis. These findings, hopefully, will help to reduce the dramatic diagnostic delay that inevitably leads to having to treat a disease in a more advanced stage with all the consequences related to delayed therapeutic action, including prolongation of the suffering of the affected patient and a considerable increase in health costs.

\section{Conflicts of Interest}

The Authors declare no conflicts of interest.

\section{Authors' Contributions}

Conceptualization: PGS and AB; methodology: RV, MC and VM; formal analysis: $\mathrm{MC}$; writing - original draft preparation: PGS and $\mathrm{AB}$; writing - review and editing: $\mathrm{PGS}$ and $\mathrm{AB}$; funding acquisition: PGS. All Authors have read and agreed to the published version of the article.

\section{Acknowledgements}

This work was supported by Fondazione Italiana Endometriosi (Grant: Progetto Clinico). The Authors would also like to thank Dr. Lia Orfei for her contribution to the statistical analysis.

\section{References}

1 Giudice LC and Kao LC: Endometriosis. Lancet 364(9447): 1789-1799, 2004. PMID: 15541453. DOI: 10.1016/S01406736(04)17403-5 
2 Bulun SE, Yilmaz BD, Sison C, Miyazaki K, Bernardi L, Liu S, Kohlmeier A, Yin P, Milad M and Wei J: Endometriosis. Endocr Rev 40(4): 1048-1079, 2019. PMID: 30994890. DOI: 10.1210/ er.2018-00242

3 Baldi A, Campioni $M$ and Signorile PG: Endometriosis: pathogenesis, diagnosis, therapy and association with cancer (review). Oncol Rep 19(4): 843-846, 2008. PMID: 18357365.

4 Signorile PG, Cassano M, Viceconte R, Spyrou M, Marcattilj V and Baldi A: Endometriosis: a retrospective analysis on diagnostic data in a cohort of 4,401 patients. In Vivo 36(1): 430438, 2022. PMID: 34972745. DOI: 10.21873/invivo.12721

5 Signorile PG, Campioni M, Vincenzi B, D'Avino A and Baldi A: Rectovaginal septum endometriosis: an immunohistochemical analysis of 62 cases. In Vivo 23(3): 459-464, 2009. PMID: 19454514

6 Fuldeore M, Chwalisz K, Marx S, Wu N, Boulanger L, Ma L and Lamothe K: Surgical procedures and their cost estimates among women with newly diagnosed endometriosis: a US database study. J Med Econ 14(1): 115-123, 2011. PMID: 21222565. DOI: $10.3111 / 13696998.2010 .549532$

7 Benagiano G and Brosens I: History of adenomyosis. Best Pract Res Clin Obstet Gynaecol 20(4): 449-463, 2006. PMID: 16515887. DOI: 10.1016/j.bpobgyn.2006.01.007

8 Signorile PG, Baldi F, Bussani R, D’Armiento M, De Falco M and Baldi A: Ectopic endometrium in human foetuses is a common event and sustains the theory of müllerianosis in the pathogenesis of endometriosis, a disease that predisposes to cancer. J Exp Clin Cancer Res 28: 49, 2009. PMID: 19358700. DOI: $10.1186 / 1756-9966-28-49$

9 Signorile PG, Baldi F, Bussani R, D’Armiento M, De Falco M, Boccellino M, Quagliuolo L and Baldi A: New evidence of the presence of endometriosis in the human fetus. Reprod Biomed Online 21(1): 142-147, 2010. PMID: 20471320. DOI: 10.1016/ j.rbmo.2010.04.002

10 Signorile PG, Baldi F, Bussani R, Viceconte R, Bulzomi P, D'Armiento M, D'Avino A and Baldi A: Embryologic origin of endometriosis: analysis of 101 human female fetuses. J Cell Physiol 227(4): 1653-1656, 2012. PMID: 21678420. DOI: $10.1002 /$ jcp. 22888

11 Bouquet de Jolinière J, Ayoubi JM, Lesec G, Validire P, Goguin A, Gianaroli L, Dubuisson JB, Feki A and Gogusev J: Identification of displaced endometrial glands and embryonic duct remnants in female fetal reproductive tract: possible pathogenetic role in endometriotic and pelvic neoplastic processes. Front Physiol 3: 444, 2012. PMID: 23227010. DOI: 10.3389/fphys.2012.00444

12 Signorile PG and Baldi A: Endometriosis: new concepts in the pathogenesis. Int J Biochem Cell Biol 42(6): 778-780, 2010. PMID: 20230903. DOI: 10.1016/j.biocel.2010.03.008

13 Signorile PG and Baldi A: New evidence in endometriosis. Int J Biochem Cell Biol 60: 19-22, 2015. PMID: 25578564. DOI: 10.1016/j.biocel.2014.12.019

14 Piriyev E and Römer T: Coincidence of uterine malformations and endometriosis: a clinically relevant problem? Arch Gynecol Obstet 302(5): 1237-1241, 2020. PMID: 32816056. DOI: 10.1007/s00404-020-05750-9

15 Crispi S, Piccolo MT, D’Avino A, Donizetti A, Viceconte R, Spyrou M, Calogero RA, Baldi A and Signorile PG: Transcriptional profiling of endometriosis tissues identifies genes related to organogenesis defects. J Cell Physiol 228(9):
1927-1934, 2013. PMID: 23460397. DOI: $10.1002 /$ jcp. 24358

16 Ballard K, Lowton $\mathrm{K}$ and Wright J: What's the delay? A qualitative study of women's experiences of reaching a diagnosis of endometriosis. Fertil Steril 86(5): 1296-1301, 2006. PMID: 17070183. DOI: 10.1016/j.fertnstert.2006.04.054

17 D'Hooghe TM, Mihalyi AM, Simsa P, Kyama CK, Peeraer K, De Loecker P, Meeuwis L, Segal L and Meuleman C: Why we need a noninvasive diagnostic test for minimal to mild endometriosis with a high sensitivity. Gynecol Obstet Invest 62(3): 136-138, 2006. PMID: 16679771. DOI: 10.1159/ 000093120

18 Signorile PG and Baldi A: Serum biomarker for diagnosis of endometriosis. J Cell Physiol 229(11): 1731-1735, 2014. PMID: 24648304. DOI: $10.1002 /$ jcp. 24620

19 Signorile PG and Baldi A: Supporting evidences for potential biomarkers of endometriosis detected in peripheral blood. Data Brief 5: 971-974, 2015. PMID: 26759817. DOI: 10.1016/ j.dib.2015.10.047

20 Signorile PG and Baldi A: Prototype of Multiplex Bead Assay for Quantification of Three Serum Biomarkers for In Vitro Diagnosis of Endometriosis. J Cell Physiol 231(12): 2622-2627, 2016. PMID: 27137486. DOI: $10.1002 /$ jcp. 25410

21 Rolla E: Endometriosis: advances and controversies in classification, pathogenesis, diagnosis, and treatment. F1000Res 8: F1000, 2019. PMID: 31069056. DOI: 10.12688/ f1000research.14817.1

22 Tanbo T and Fedorcsak P: Endometriosis-associated infertility: aspects of pathophysiological mechanisms and treatment options. Acta Obstet Gynecol Scand 96(6): 659-667, 2017. PMID: 27998009. DOI: 10.1111/aogs.13082

23 Bellelis P, Dias JA Jr, Podgaec S, Gonzales M, Baracat EC and Abrão MS: Epidemiological and clinical aspects of pelvic endometriosis-a case series. Rev Assoc Med Bras (1992) 56(4): 467-471, 2010. PMID: 20835646. DOI: 10.1590/s010442302010000400022

24 Signorile PG, Viceconte $\mathrm{R}$ and Baldi A: Novel dietary supplement association reduces symptoms in endometriosis patients. J Cell Physiol 233(8): 5920-5925, 2018. PMID: 29243819. DOI: $10.1002 /$ jcp. 26401

25 Coxon L, Horne AW and Vincent K: Pathophysiology of endometriosis-associated pain: A review of pelvic and central nervous system mechanisms. Best Pract Res Clin Obstet Gynaecol 51: 53-67, 2018. PMID: 29525437. DOI: 10.1016/ j.bpobgyn.2018.01.014

26 DiBenedetti D, Soliman AM, Gupta C and Surrey ES: Patients' perspectives of endometriosis-related fatigue: qualitative interviews. J Patient Rep Outcomes 4(1): 33, 2020. PMID: 32377820. DOI: $10.1186 / \mathrm{s} 41687-020-00200-1$

27 Boneva RS, Lin JS, Wieser F, Nater UM, Ditzen B, Taylor RN and Unger ER: Endometriosis as a comorbid condition in chronic fatigue syndrome (CFS): secondary analysis of data from a CFS case-control study. Front Pediatr 7: 195, 2019. PMID: 31179251. DOI: 10.3389/fped.2019.00195

28 O'Rahilly R: Prenatal human development. In: Biology of the Uterus. Wynn RM (ed.). Boston, MA, USA, Springer, pp. 35-57, 1977.

29 Wu CC, Chung SD and Lin HC: Endometriosis increased the risk of bladder pain syndrome/interstitial cystitis: A populationbased study. Neurourol Urodyn 37(4): 1413-1418, 2018. PMID: 29318645. DOI: $10.1002 /$ nau.23462 
30 Cervigni M and Natale F: Gynecological disorders in bladder pain syndrome/interstitial cystitis patients. Int J Urol 21 Suppl 1: 85-88, 2014. PMID: 24807511. DOI: 10.1111/iju.12379

31 Cozzolino M, Coccia ME, Lazzeri G, Basile F and Troiano G: Variables associated with endometriosis-related pain: a pilot study using a visual analogue scale. Rev Bras Ginecol Obstet 41(3): 170-175, 2019. PMID: 30991431. DOI: 10.1055/s-00391679879

32 Bourdel N, Alves J, Pickering G, Ramilo I, Roman H and Canis M: Systematic review of endometriosis pain assessment: how to choose a scale? Hum Reprod Update 21(1): 136-152, 2015. PMID: 25180023. DOI: 10.1093/humupd/dmu046

33 Sayasneh A, Tsivos D and Crawford R: Endometriosis and ovarian cancer: a systematic review. ISRN Obstet Gynecol 2011: 140310, 2011. PMID: 21789283. DOI: 10.5402/2011/140310

34 Signorile PG and Baldi A: Looking for an effective and noninvasive diagnostic test for endometriosis: where are we? Ann Transl Med 6(Suppl 2): S106, 2018. PMID: 30740427. DOI: 10.21037/atm.2018.11.46

35 Harrison V, Rowan K and Mathias J: Stress reactivity and family relationships in the development and treatment of endometriosis. Fertil Steril 83(4): 857-864, 2005. PMID: 15820791. DOI: 10.1016/j.fertnstert.2004.10.033

36 Sinaii N, Cleary SD, Ballweg ML, Nieman LK and Stratton P: High rates of autoimmune and endocrine disorders, fibromyalgia, chronic fatigue syndrome and atopic diseases among women with endometriosis: a survey analysis. Hum Reprod 17(10): 2715-2724, 2002. PMID: 12351553. DOI: 10.1093/humrep/17.10.2715

37 Appleyard CB, Flores I and Torres-Reverón A: The link between stress and endometriosis: from animal models to the clinical scenario. Reprod Sci 27(9): 1675-1686, 2020. PMID: 32542543. DOI: $10.1007 / \mathrm{s} 43032-020-00205-7$
38 Marinho MCP, Magalhaes TF, Fernandes LFC, Augusto KL, Brilhante AVM and Bezerra LRPS: Quality of life in women with endometriosis: an integrative review. J Womens Health (Larchmt) 27(3): 399-408, 2018. PMID: 29064316. DOI: 10.1089/jwh.2017.6397

39 Casalechi M, Vieira-Lopes M, Quessada MP, Arão TC and Reis FM: Endometriosis and related pelvic pain: association with stress, anxiety and depressive symptoms. Minerva Obstet Gynecol 73(3): 283-289, 2021. PMID: 34008383. DOI: 10.23736/S2724-606X.21.04704-3

40 Allen PR: Chronic fatigue syndrome: implications for women and their health care providers during the childbearing years. J Midwifery Womens Health 53(4): 289-301; quiz 399, 2008. PMID: 18586181. DOI: 10.1016/j.jmwh.2007.12.001

41 Uduwela AS, Perera MA, Aiqing L and Fraser IS: Endometrialmyometrial interface: relationship to adenomyosis and changes in pregnancy. Obstet Gynecol Surv 55(6): 390-400, 2000. PMID: 10841317. DOI: $10.1097 / 00006254-200006000-00025$

42 Brown J, Crawford TJ, Datta S and Prentice A: Oral contraceptives for pain associated with endometriosis. Cochrane Database Syst Rev 5: CD001019, 2018. PMID: 29786828. DOI: 10.1002/14651858.CD001019.pub3

43 Bulun SE, Takayama K, Suzuki T, Sasano H, Yilmaz B and Sebastian S: Organization of the human aromatase p450 (CYP19) gene. Semin Reprod Med 22(1): 5-9, 2004. PMID: 15083376. DOI: $10.1055 / \mathrm{s}-2004-823022$

Received January 6, 2022

Revised January 31, 2022

Accepted February 9, 2022 